\title{
Prediction of the Fragmentation Pathway of Atorvastatin by Using High Resolution Collision Induced Dissociation (HR-MS/MS) Spectral Information
}

\author{
Dev Kant Shandilya ${ }^{1}{ }^{*}$, Rekha Israni ${ }^{1}$, Peter Edward Joseph ${ }^{2}$, \\ Venkata Siva Satyanarayana Kantamreddi ${ }^{3}$ \\ ${ }^{1}$ Department of Research, Bhagwant University, Ajmer, India \\ ${ }^{2}$ Department of Chemistry, St. John's College, Agra, India \\ ${ }^{3}$ Centre for Chemical Analysis, Central Research Laboratory, GIT, GITAM University, Visakhapatnam, India \\ Email: *shandilya@yahoo.com, *devkantshandilya@hotmail.com
}

How to cite this paper: Shandilya, D.K., Israni, R., Joseph, P.E. and Kantamreddi, V.S.S. (2017) Prediction of the Fragmentation Pathway of Atorvastatin by Using High Resolution Colli- sion Induced Dissociation (HR-MS/MS) Spec- tral Information. Open Access Library Jour- nal, 4: e3473.

https://doi.org/10.4236/oalib.1103473

Received: February 21, 2017

Accepted: March 27, 2017

Published: March 30, 2017

Copyright $\odot 2017$ by authors and Open Access Library Inc.

This work is licensed under the Creative Commons Attribution International License (CC BY 4.0).

http://creativecommons.org/licenses/by/4.0/

\begin{abstract}
Introduction: A possible fragmentation pathway of atorvastatin was proposed based on rational interpretation of high resolution collision induced dissociation (CID) fragmentation spectral data. Method: The mass spectral (MS and MS/MS) data of atorvastatin was obtained by using a flow injection analysis, LC coupled with high resolution mass analyzer system with Q-TOF technology. Results: The elemental composition for each major fragment was proposed with a calculated mass error in parts per million ( $\mathrm{ppm}$ ). The mass error found in this study is from 0.3 to $5.7 \mathrm{ppm}$; strongly supports all the proposed elemental composition of fragments. Based on the fragments, possible fragmentation pathway was proposed. Conclusion: The workflow followed for interpretation can also address the structural possibilities of similar type of small organic molecules.
\end{abstract}

\section{Subject Areas}

Analytical Chemistry, Chemistry \& Materials Science

\section{Keywords}

Atorvastatin, Small Drug Molecules, High Resolution Mass Spectrometry,

Fragmentation, Rational Workflow, Interpretation

\section{Introduction}

A variety of spectroscopic techniques are available for the identification and 
characterization of drug molecules. One of the most advanced analytical tools is high resolution mass spectrometry (HRMS) that has become the method of choice in structural characterization of small molecules, drug products, proteins and metabolites in different biological matrix [1] [2] [3] [4]. With advancements in ionization methods and instrumentation, high performance liquid chromatography coupled with high resolution mass spectrometry (LC-HRMS) has become a powerful tool for the research [5]-[11]. Interpretation of the fragmentation spectra and establishment of fragments structures are most time taking and essential tasks. The workflow [12] for the interpretation of the full scan atmospheric pressure ionization mass spectra (MS) and collision induced dissociation fragmentation spectra (MS/MS) of small organic molecules was efficiently applied for structural conformational studies; small nitrogenous organic molecule with hydroxyl and carboxylic acid functional group; atorvastatin was selected for this study.

Atorvastatin [13] [14] [15] is an inhibitor of 3-hydroxy-3-methylglutarylcoenzyme A (HMG-CoA) reductase. This enzyme catalyzes the conversion of HMG-CoA to mevalonate, an early and rate-limiting step in cholesterol biosynthesis. It is used primarily as a lipid-lowering agent and for prevention of events associated with cardiovascular disease especially people with type 2 diabetes, coronary heart disease, or other risk factors. It is an off-white crystalline powder and chemically known as Calcium-(3R,5R)-7-[2-(4-fluorphenyl)-5-isopropyl3-phenyl-4-(phenylcarbamoyl)-1H-pyrrol-1-yl]-3,5-dihydroxyheptanoathydrat(1:2: 3). The empirical formula of atorvastatin calcium trihydrate is $\left(\mathrm{C}_{66} \mathrm{H}_{68} \mathrm{CaF}_{2}\right.$ $\left.\mathrm{N}_{4} \mathrm{O}_{10}\right) 3 \mathrm{H}_{2} \mathrm{O}$ and its molecular weight is 1209.4. Atorvastatin free form empirical formula is $\mathrm{C}_{33} \mathrm{H}_{35} \mathrm{FN}_{2} \mathrm{O}_{5}$; monoisotopic molecular weight is 558.2530 and molecular structure of atorvastatin free form is presented in Figure 1.

During this study, high resolution mass spectral data of atorvastatin was generated using electrospray ionization and collision induced dissociation, followed by interpretation using basic interpretation rules and rational workflow [12] approach.

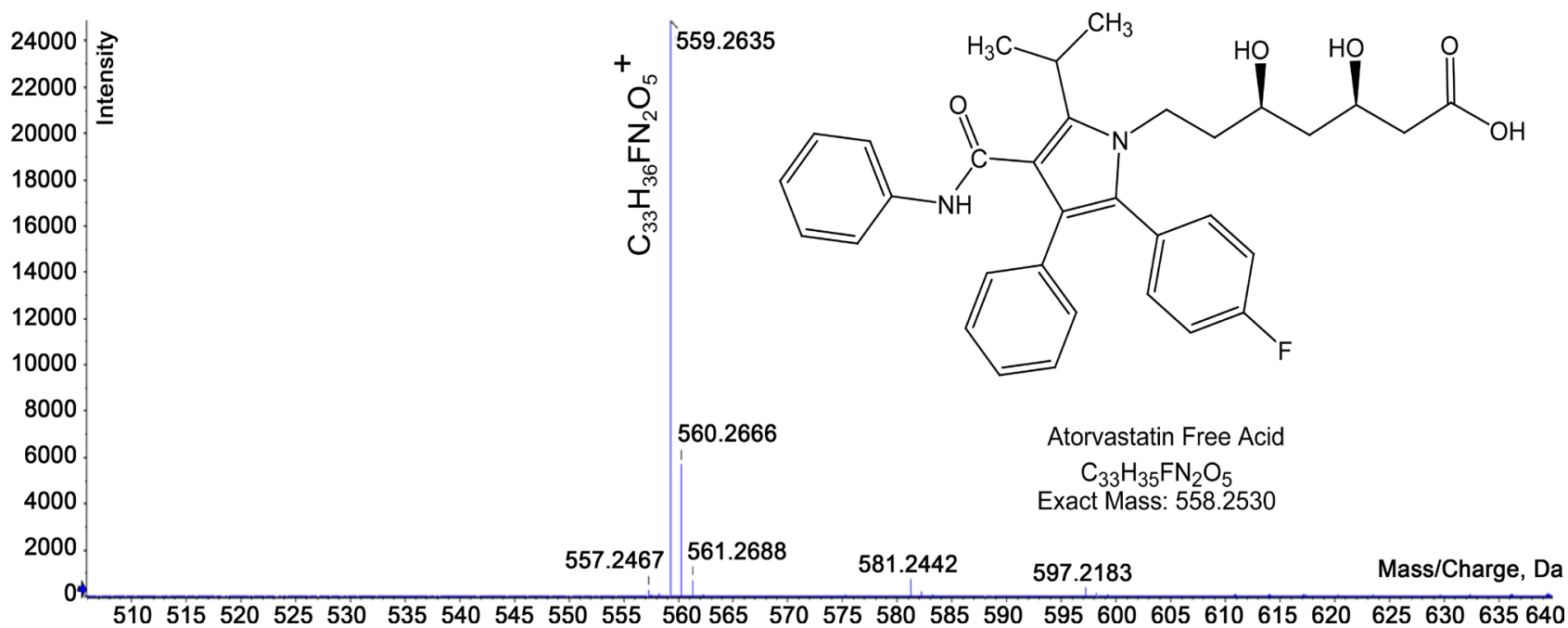

Figure 1. HRMS spectrum of atorvastatin using $\mathrm{ESI}^{+}$ion source. 


\section{Experiment}

\subsection{Drug Sample}

Atorvastatin was extracted from generic dosage form. A final concentration was about $10 \mu \mathrm{g} / \mathrm{ml}$ in water and methanol for mass spectrometric studies.

\subsection{Chemicals and Reagents}

The ultrapure water (18.2 M $\Omega$ ) was obtained using MilliQ apparatus from Millipore (Milford, USA) and the HPLC grade methanol was purchased from J.T. Baker.

\subsection{Instrumentation}

Shimadzu Prominence 20 AD HPLC (Kyto Japan) was coupled with Triple TOF (AB SCIEX) high resolution mass spectrometer system equipped with dual ionization (electrospray ionization and atmospheric pressure chemical ionization) source was used for this analysis. External calibrant delivery system (CDS) was used to calibrate the TOF mass analyzer with APCI small molecules calibration solution provided by instrument vendor.

\subsection{Chromatographic and Mass Spectrometric Conditions}

The extracted drug sample of atorvastatin was subjected to high resolution MS and MS/MS analysis via flow injection analysis (FIA) mode; liquid chromatography system was used to introduce the sample to mass spectrometer ion source. Liquid chromatography system set to isocratic flow $0.1 \mathrm{ml} / \mathrm{min}$ of mobile phase water and methanol in a ratio of 1:1 and injection volume was $10 \mu \mathrm{l}$. Electrospray ion source was selected to achieve the intense protonated parent ion and high resolution mass analyzer selected to get the accurate mass; which supports to predict the right elemental composition. Spray voltage and collision energy optimized by using direct infusion mode to get optimum quality to spectral data. Experiments were acquired using optimized parameters; spray voltage of $+5.0 \mathrm{kV}$ for MS and collision energy (CE) setting of $35 \mathrm{~V}$ with a spread of \pm 15 $\mathrm{V}$ applied to all parent ions for CID (collision induced dissociation) for MS/MS.

\section{Results and Discussion}

The LC coupled with HRMS technique is a modern alternative method for the identification of small molecules and their impurities. The experimental data (MS and MS-MS spectral data) of atorvastatin was generated using a high performance liquid chromatography (HPLC) coupled with high resolution mass spectrometer system (HRMS) with Time of Flight (TOF) mass analyzer via Flow Injection Analysis (FIA) mode and Electro-spray Ionization (ESI ${ }^{+}$) ion source.

The full scan accurate mass and product ion spectrum of atorvastatin was obtained from IDA (information dependent acquisition) experiments. The workflow [12] was applied for the interpretation of high resolution MS and 
MS/MS spectral data; molecular ion peak was displayed $[\mathrm{M}+\mathrm{H}]^{+}$at $\mathrm{m} / \mathrm{z}$ $559.2635 \mathrm{Da}$. The most typical adduct $[\mathrm{M}+\mathrm{Na}]^{+}$at $\mathrm{m} / z 581.2442$ with a less abundant adduct $[\mathrm{M}+\mathrm{K}]^{+}$at 597.2183 in mass spectrum of atorvastatin is further confirming the molecular ion peak at $\mathrm{m} / z 559.2635$ with empirical formula $\mathrm{C}_{33} \mathrm{H}_{36} \mathrm{FN}_{2} \mathrm{O}_{5}^{+}$(Figure 1).

The TOF MS/MS spectrum of atorvastatin also exhibited molecular ion peak at $\mathrm{m} / z 559.2635 \mathrm{Da}$ as $[\mathrm{M}+\mathrm{H}]^{+}$(calculated for $\mathrm{C}_{33} \mathrm{H}_{36} \mathrm{FN}_{2} \mathrm{O}_{5}^{+}$, exact mass 559.2603, difference $5.7 \mathrm{ppm}$, Figure 2 and Table 1). It was further fragmented in collision cell (Q2) into eleven major fragments at $\mathrm{m} / z$ 250.1038, 276.1194, $292.1508,318.1654,362.1561,380.1675,404.2032,422.2139,440.2239,448.1936$ and 466.2046. The elemental composition, exact mass, assigned structures and mass error of these major fragments were illustrated in Figure 2 and Table 1. Predicted fragmentation pathway also presented in Figure 2; the molecular ion peak ( $\mathrm{m} / z 559.2635 \mathrm{Da}$ ) was initially fragmented into $\mathrm{m} / z 466.2046$ (calculated formula $\mathrm{C}_{27} \mathrm{H}_{29} \mathrm{FNO}_{5}^{+}$, exact mass 466.2024 , mass error $4.7 \mathrm{ppm}$ ) by the loss of $\mathrm{C}_{6} \mathrm{H}_{7} \mathrm{~N}$, fragment ion 466.2046 yielded two ions at $\mathrm{m} / \mathrm{z} 448.1936$ (calculated formula $\mathrm{C}_{27} \mathrm{H}_{27} \mathrm{FNO}_{4}^{+}$, exact mass 448.1919 , mass error $3.8 \mathrm{ppm}$ ) and 440.2239 (calculated formula $\mathrm{C}_{26} \mathrm{H}_{31} \mathrm{FNO}_{4}^{+}$, exact mass 440.2232 , mass error $1.6 \mathrm{ppm}$ ) by loss of water and by loss of CO, respectively. Fragment $\mathrm{m} / \mathrm{z} 440.2239$ was further fragmented into two ions at $\mathrm{m} / z 422.2139$ (calculated formula $\mathrm{C}_{26} \mathrm{H}_{29} \mathrm{FNO}_{3}^{+}$, exact mass 422.2126, mass error $3.1 \mathrm{ppm}$ ) and 292.1508 (calculated formula $\mathrm{C}_{20} \mathrm{H}_{19} \mathrm{FN}^{+}$, exact mass 292.1496, mass error $4.1 \mathrm{ppm}$ ) by loss of a water molecule and $\mathrm{C}_{4} \mathrm{H}_{12} \mathrm{O}_{4}$, respectively. Further, a loss of water and $\mathrm{C}_{3} \mathrm{H}_{6}$ to the ion with $\mathrm{m} / \mathrm{Z}$ 422.2139 lead fragment ions $\mathrm{m} / z 404.2032$ (calculated formula $\mathrm{C}_{26} \mathrm{H}_{27} \mathrm{FNO}_{2}^{+}$,

Table 1. Interpretation of MS/MS spectra of atorvastatin based on rational work flow [12].

\begin{tabular}{ccccccc}
\hline $\begin{array}{c}\text { Measured } \\
\text { Mass }(\boldsymbol{m} / \mathbf{z})\end{array}$ & $\begin{array}{c}\text { Electron } \\
\text { Paring }\end{array}$ & $\begin{array}{c}\text { Nitrogen } \\
\text { Rule }\end{array}$ & $\begin{array}{c}\text { No. of } \\
\text { Nitrogen }(\mathrm{s})\end{array}$ & $\begin{array}{c}\text { Proposed } \\
\text { Formula }\end{array}$ & $\begin{array}{c}\text { Calculated } \\
\text { Mass }(\boldsymbol{m} / \mathbf{z})\end{array}$ & $\begin{array}{c}\text { Error } \\
(\mathrm{ppm})\end{array}$ \\
\hline 559.2635 & {$[\mathrm{M}+\mathrm{H}]^{+}$} & $\mathrm{EN}$ & 2 & $\mathrm{C}_{33} \mathrm{H}_{36} \mathrm{FN}_{2} \mathrm{O}_{5}^{+}$ & 559.2603 & 5.7 \\
466.2046 & EE & $\mathrm{ON}$ & 1 & $\mathrm{C}_{27} \mathrm{H}_{29} \mathrm{FNO}_{5}^{+}$ & 466.2024 & 4.7 \\
448.1936 & EE & ON & 1 & $\mathrm{C}_{27} \mathrm{H}_{27} \mathrm{FNO}_{4}^{+}$ & 448.1919 & 3.8 \\
440.2239 & EE & ON & 1 & $\mathrm{C}_{26} \mathrm{H}_{31} \mathrm{FNO}_{4}^{+}$ & 440.2232 & 1.6 \\
422.2139 & EE & ON & 1 & $\mathrm{C}_{26} \mathrm{H}_{29} \mathrm{FNO}_{3}^{+}$ & 422.2126 & 3.1 \\
404.2032 & EE & ON & 1 & $\mathrm{C}_{26} \mathrm{H}_{27} \mathrm{FNO}_{2}^{+}$ & 404.2020 & 3.0 \\
380.1675 & EE & ON & 1 & $\mathrm{C}_{23} \mathrm{H}_{23} \mathrm{FNO}_{3}^{+}$ & 380.1656 & 5.0 \\
362.1561 & EE & ON & 1 & $\mathrm{C}_{23} \mathrm{H}_{21} \mathrm{FNO}_{2}^{+}$ & 362.1551 & 2.8 \\
318.1654 & EE & ON & 1 & $\mathrm{C}_{22} \mathrm{H}_{21} \mathrm{FN}^{+}$ & 318.1653 & 0.3 \\
292.1508 & EE & ON & 1 & $\mathrm{C}_{20} \mathrm{H}_{19} \mathrm{FN}^{+}$ & 292.1496 & 4.1 \\
276.1194 & EE & ON & 1 & $\mathrm{C}_{19} \mathrm{H}_{15} \mathrm{FN}^{+}$ & 276.1183 & 4.0 \\
250.1038 & EE & ON & 1 & $\mathrm{C}_{17} \mathrm{H}_{13} \mathrm{FN}^{+}$ & 250.1027 & 4.4 \\
\hline
\end{tabular}

EE: even electron; EN: even nitrogen; ON: odd nitrogen; ${ }^{\star}$ Mass error $=$ difference between measured accurate mass and calculated accurate mass/calculated accurate mass $\times 10^{6}$. 


$$
\begin{aligned}
& \text { offerar } \\
& \text { bo } \\
& \text { ba }
\end{aligned}
$$

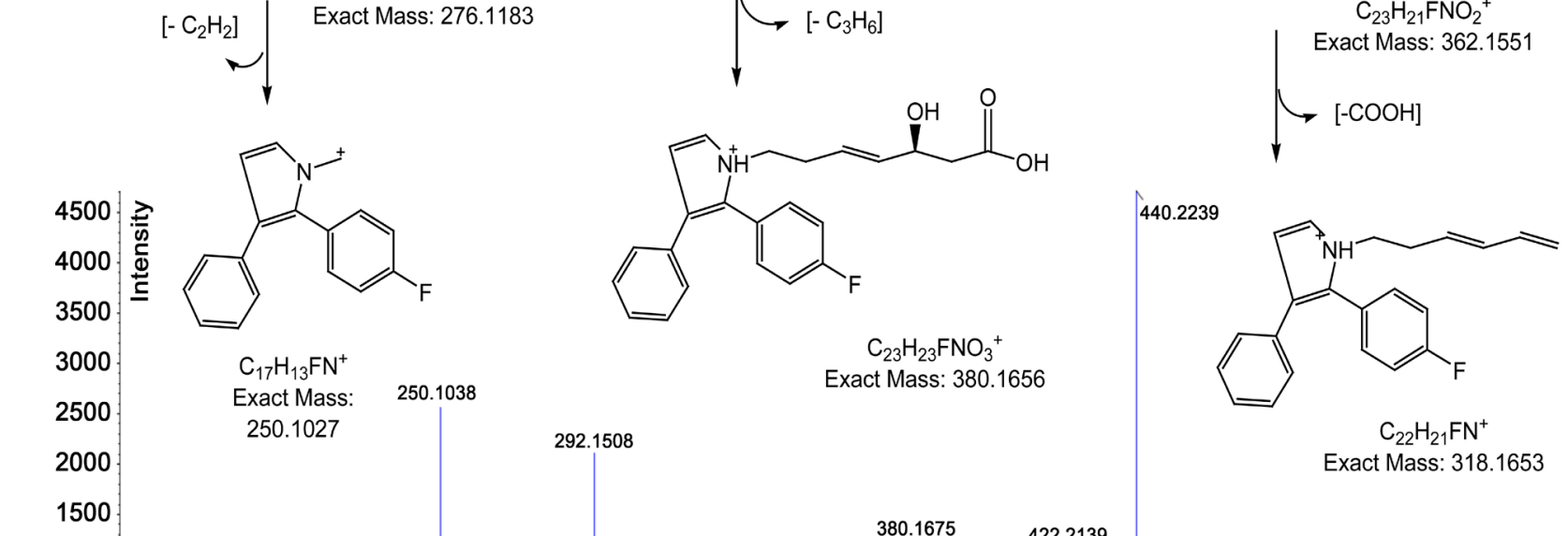


exact mass 404.2020, mass error $3.0 \mathrm{ppm}$ ) and 380.1675 (calculated formula $\mathrm{C}_{23} \mathrm{H}_{23} \mathrm{FNO}_{3}^{+}$, exact mass 380.1656, mass error $5.0 \mathrm{ppm}$ ) was observed, respectively. The fragment ion with $m / z 362.1561$ (calculated formula $\mathrm{C}_{23} \mathrm{H}_{21} \mathrm{FNO}_{2}^{+}$, exact mass 362.1551 , mass error $2.8 \mathrm{ppm}$ ) shows a loss of $\mathrm{C}_{3} \mathrm{H}_{6}$ to a fragment ion with $m / Z$ 404.2032, which was further fragmented at $m / Z 318.1654$ (calculated formula $\mathrm{C}_{22} \mathrm{H}_{21} \mathrm{FN}^{+}$, exact mass 318.1653 , mass error $0.3 \mathrm{ppm}$ ) corresponding to the loss of $\mathrm{COOH}$.

The fragment at $\mathrm{m} / z 292.1508$ (calculated formula $\mathrm{C}_{20} \mathrm{H}_{19} \mathrm{FN}^{+}$, exact mass 292.1496, mass error $4.1 \mathrm{ppm}$ ) corresponding to the loss of $\mathrm{C}_{4} \mathrm{H}_{12} \mathrm{O}_{4}$ from the ion $\mathrm{m} / z$ 440.2239. A subsequent fragment of ion $\mathrm{m} / z 292.1508$ resulting peak at $\mathrm{m} / z$ 276.1194 (calculated formula $\mathrm{C}_{19} \mathrm{H}_{15} \mathrm{FN}^{+}$, exact mass 276.1183 , mass error 4.0 ) by losing methane, which further resulted an ion at $\mathrm{m} / z 250.1038$ (calculated formula $\mathrm{C}_{17} \mathrm{H}_{13} \mathrm{FN}^{+}$, exact mass 250.1027 , mass error $4.4 \mathrm{ppm}$ ) corresponding to the loss of $\mathrm{C}_{2} \mathrm{H}_{2}$. Fragmentation pathway described above and presented in figure no. 2 is a probable pathway; formation of fragments can be simultaneous because of multiple transitions can occur simultaneously.

\section{Conclusion}

The molecular ion peak as $[\mathrm{M}+\mathrm{H}]^{+}$in $\mathrm{MS} / \mathrm{MS}$ spectra of atorvastatin appeared at $m / z 559.2635 \mathrm{Da}$. Further, the CID fragmentation of protonated $[\mathrm{M}+\mathrm{H}]^{+}$ion generated and interpretation was carried followed by the proposal of fragmentation pathway (based on neutral losses, single and multiple bond cleavages). Fragmentation pathway is only a predication. Pathway can be different and there are some other probabilities also considering the occurrence of multiple transitions simultaneously. The mass error found in this study is 0.3 to $5.7 \mathrm{ppm}$, which strongly supports the fragment ions molecular structures and elemental composition. Nowadays various software tools are available for the interpretation of mass spectrometry data; during the study no software tool was used for interpretation, predication of the fragments structure and pathway of formation. In addition to above, the study also provides the insights about workflow based interpretation of parent and product ion spectra in combination with the basic rules. The workflow [12] applied in this study was found efficient and can be applied for structure verification studies of small organic molecules and for identification of similar type of drug molecules or small organic molecules and their impurities.

\section{Acknowledgements}

This paper is part of Ph.D thesis of Dev Kant Shandilya. Author expresses his gratitude to the Dean, Department of Research, Bhagwant University, Ajmer, Rajasthan, India for extending his constant support.

\section{Conflicts of Interest}

Declared none. 


\section{References}

[1] Gorog, S. (2005) The Sacred Cow: The Questionable Role of Assay Methods in Characterising the Quality of Bulk Pharmaceuticals. Journal of Pharmaceutical and Biomedical Analysis, 36, 931-937. https://doi.org/10.1016/j.jpba.2004.06.025

[2] Domon, B. and Aebersold, R. (2006) Mass Spectrometry and Protein Analysis. Science, 312, 212-217. https://doi.org/10.1126/science.1124619

[3] Pramanik, B.N., Bartner, P.L. and Chen, G. (1999) The Role of Mass Spectrometry in the Drug Discovery Process. Current Opinion in Drug Discovery \& Development, 2, 401-417.

[4] Nicolas, C.E. and Schoolz, T.H. (1998) Active Drug Substances Impurity Profiling Part II. LC/MS/MS Fingerprinting. Journal of Pharmaceutical and Biomedical Analysis, 16, 825-836. https://doi.org/10.1016/S0731-7085(97)00132-5

[5] Cooks, R.G., Chen, G., Wong, P. and Wollnik, H. (1997) Mass Spectrometers. In: Trigg, G.L., Ed., Encyclopedia of Applied Physics, Vol. 19, VCH Publishers, New York, 289.

[6] Chen, G., Pramanik, B.N., Liu, Y.-H. and Mirza, U.A. (2007) Applications of LC/MS in Structure Identifications of Small Molecules and Proteins in Drug Discovery. Journal of Mass Spectrometry, 42, 279-287. https://doi.org/10.1002/jms.1184

[7] Kumar, Y.R., Babu, J.M., Sarma, M.S.P., Seshidhar, B., Reddy, S.S., Reddy, G.S. and Vyas, K. (2003) Application of LC-MS/MS for the Identification of a Polar Impurity in Mosapride, a Gastroprokinetic Drug. Journal of Pharmaceutical and Biomedical Analysis, 32, 361-368. https://doi.org/10.1016/S0731-7085(03)00076-1

[8] Ermer, J. (1998) The Use of Hyphenated LC-MS Technique for Characterisation of Impurity Profiles during Drug Development. Journal of Pharmaceutical and Biomedical Analysis, 18, 707-714. https://doi.org/10.1016/S0731-7085(98)00267-2

[9] Angelika, G., Harrison, M.W., Herniman, J.M., Skylaris, C.-K. and Langely, G.J. (2013) A Predictive Science Approach to Aid Understanding of Electrospray Ionization Trandem Mass Spectrometric Fragmentation Pathway of Small Molecules Using Density Functional Calculations. Rapid Communications in Mass Spectrometry, 27, 964-970. https://doi.org/10.1002/rcm.6536

[10] Kumar, A., Darekar, G., Ramagiri, S., Bhasin, N., Pillai, M. and Shandilya, D.K. (2015) Generic Workflow Using Advanced Analysis and Data Interpretation Tools for Identification of Irbesartan Degradation Products by Liquid Chromatography to High Resolution Mass Spectrometry. ACAIJ, 15, 352-363.

[11] Pillai, M.G., Kumar, A., Sharma, R. and Bhasin, N. (2014) LC-MS Based Workflows for Qualitative and Quantitative Analysis for Homeopathic Preparation of Hydrastis Canadensis. Chromatographia, 7, 119-131. https://doi.org/10.1007/s10337-013-2577-5

[12] Shandilya, D.K., Joseph, P.E. and Kantamreddi, V.S.S. (2017) Interpretation of Full Scan Atmospheric Pressure Ionization Mass Spectra (MS) and Collision Induced Dissociation Fragmentation Spectra (MS/MS) of Small Organic Molecules-A Mini Review. Systematic Reviews in Pharmacy, 8, 23-25. https://doi.org/10.5530/srp.2017.1.9

[13] https://en.wikipedia.org/wiki/Atorvastatin

[14] http://www.drugs.com/atorvastatin.html

[15] http://www.rxlist.com/lipitor-drug.htm 


\section{Abbreviations}

LC: Liquid chromatography;

HPLC: High performance liquid chromatography;

MS: Mass spectrometry;

HRMS: High resolution mass spectrometer;

MS/MS: Tandem mass spectrum;

$\mathrm{m} / \mathrm{z}: \quad$ mass-to-charge ratio;

API: Atmospheric pressure ionization;

APCI: Atmospheric pressure chemical ionization;

ESI: Electrospray ionization;

CID: Collision induced dissociation;

Q-TOF: Quadrupole-Time of Flight;

IDA: Information dependent acquisition;

FIA: Flow Injection Analysis

Submit or recommend next manuscript to OALib Journal and we will provide best service for you:

- Publication frequency: Monthly

- 9 subject areas of science, technology and medicine

- Fair and rigorous peer-review system

- Fast publication process

- Article promotion in various social networking sites (LinkedIn, Facebook, Twitter, etc.)

- Maximum dissemination of your research work

Submit Your Paper Online: Click Here to Submit

Or Contact service@oalib.com 